\author{
ГЕННАДИЙ МАНАЕНКО \\ Северо-Кавказский федеральный университет (Ставрополь, Россия)
}

\title{
Три научных облика одного абстрактного объекта
}

Современная наука характеризуется стремлением к интеграции знаний, становлением комплексного подхода к изучаемым объектам, с одной стороны, и в то же время дифференциацией научного знания, созданием смежных научных дисциплин, разнообразием школ и направлений в каждой из них, с другой стороны. И чем сложнее, многограннее объект исследования, тем больше существует точек зрения на него и аспектов его анализа, что приводит к известной параллельности знания, его дублированию, опосредованному различием целей, задач и предмета исследования в каждой научной дисциплине, уровня представления и степени абстракции изучаемого объекта, а также разными методологическими подходами и разнообразием частных методик анализа, несовпадением используемых терминологических систем.

Одной из областей пересечения трех наук - лингвистики, психолингвистики и когнитологии - является абстрактный объект, подводимый в этих науках, соответственно, под понятия семантический уровень, внутренняя речь, ментальный лексикон и представляющий важнейший исходный пункт в теоретических исследованиях. С данными понятиями неразрывно связано разрешение таких проблем, как соотношение языка и мышления, значения и смысла, ментальных репрезентаций и типов структур знаний, индивидуального и социального знания, понимание и описание механизмов мышления и процессов порождения / восприятия речи, принципов вербальной коммуникации. В этой связи представляется уместным подвергнуть критическому анализу и в определённой степени гармонизировать понятия семантический уровень (СУ), внутренняя речь (ВР) и ментальный лексикон (МЛ).

Поскольку язык - это прежде всего, как отмечает И. М. Кобозева, средство выражения и передачи информации, то практически любой аспект его формальной структуры, за исключением определяемых ограничениями, которые обусловлены биологической природой человека, например, фонетического, имеет в основе семантическую мотивировку (Кобозева 2000: 3). Таким образом, семантика выступает в лингвистике как раздел, изучающий содержание единиц языка, которое предстаёт в двух ипостасях: значение 
и смысл. При этом «... понятие значения в обыденном сознании связано с презумпцией существования знаковой системы, элементом или текстом которой выступает носитель значения (языковое выражение - Г. М.). Понятие смысла такой презумпции не имеет» (Кобозева 2000: 11). Отсюда следует, что значение языкового выражения - это информация, связанная с ним конвенциально, т.е. в соответствии с общепринятыми правилами использования данного языкового выражения в качестве средства передачи информации (интерпсихический, социализированный модус содержания). Смысл же языкового выражения - это информация, связанная с ним в сознании субъекта коммуникации в период времени Т, когда он производит языковое выражение в качестве средства передачи информации (интрапсихический, индивидуализированный модус содержания). Следовательно, понятие смысл детерминирует не только обязательность субъекта сознания, но и момента коммуникации, что приводит к следующему постулату о границах семантики: «К области семантики (в широком смысле) относится вся информация, которую имеет в виду говорящий при развёртывании высказывания и которую необходимо восстановить слушающему для правильной интерпретации этого высказывания» (Кибрик 2001: 25).

Здесь необходимо сделать следующее уточнение. Поскольку не только предметная отнесенность, но и способ такого соотнесения и правила употребления языкового выражения подчинены правилам, общепринятым в определенной языковой общности, можно сделать вывод, что «значение является социально кодифицированной формой общественного опыта, присваиваемого каждым индивидом» (Леонтьев 2001: 145). Однако, как пишет А. А. Леонтьев, если «взглянуть на значение как на факт психики, как на фрегевское «представление», а не «значение», то можно заметить парадоксальную вещь. Хотя значение объективно для каждого индивида, оно никогда не выступает как объективное явление. Дело не в том, каковы индивидуальные вариации при усвоении данного значения, какова разница в «чувственных впечатлениях, которые человек имел раньше», и т.п., дело в том, что, усваивая общественный опыт, зафиксированный в значениях, индивид включает его в систему своих жизненных отношений, в систему своей деятельности. И в первую очередь это сказывается в том, что всякое содержание, закрепленное в значении, воспринимается человеком по-разному, в зависимости от мотива соответствующей деятельности. < .. > Итак, если попытаться определить смысл в нашем понимании, то вернее всего будет говорить о нем как об аналоге значения в конкретной деятельности. Но это ни в коей мере не просто индивидуально-психологический аспект значения и тем более - не его аффективная окраска» (Леонтьев 2001: 146).

Так как восприятие одного и того же языкового выражения может быть различным у представителей разных общественных слоев (идеологичность знака, по М. М. Бахтину), то можно сделать вывод о том, что смысл так же 
не индивидуален, как и языковое значение, ибо отношение людей к действительности всегда зависит от групповых интересов: «Таким образом, смысл, как и значение, есть форма воздействия общества на отдельного человека, форма общественного опыта, усваиваемого индивидом. Но, в отличие от значения, эта форма не кодифицированная. Как правило, смысл не существует для человека-носителя этого смысла как что-то отдельное от значения; напротив, человеку кажется, что он непосредственно воспринимает денотат (или слово) в его собственном значении. Но все предметы человеческой действительности, как и все слова человеческого языка, видятся каждому из нас как бы сквозь призму нашего «личного» (а на деле общественного) интереса. И нужно специальное усилие аналитической мысли, чтобы встать над этим интересом и уловить раздельность смысла и значения» (Леонтьев 2001: 149-150).

В лингвистической семантике нашего времени даже при узкой её трактовке, как и в психолингвистике, обязательно различают языковое значение, в частности слова, и связанные с ним мыслительные структуры, поскольку «значения не функционируют по отдельности, а в определённых связях, которые к тому же складываются во всё более обширные объединения: кластеры (группы), поля, сети. Заметим, что в качестве единиц («узлов») в сети по трактовке различных авторов выступают ассоциации, пропозиции, фреймы, наборы признаков и т.д.» (Залевская 2000: 115). Также предприняты попытки учёта созидающей роли субъекта коммуникации. Во-первых, наряду с пониманием языкового значения как средства категоризации мира в аристотелевском понимании, принимается и концепция прототипического значения на основе «фамильного сходства» в духе позднего Л. Витгенштейна: действительно, у разных индивидов с тем или иным конвенциальным значением могут ассоциироваться и актуализироваться разные признаки одной и той же категории. Во-вторых, особенно в психолингвистике, значение перестаёт пониматься как образ вещи, сама вещь, а предстаёт актом, способом видения мира, т.е. идеальным действием, именем которого и является знак, что позволяет действию сохраняться, репрезентироваться вне реальных обстоятельств. Понимание значения не как образа внешнего мира, а как результата опыта было заявлено и в лингвистике. Так, почти 50 лет назад Т. Де Мауро, поддерживая представление слова как семантической сущности, функционирующей в предложении в качестве гипосемы, писал: «Соотнесённость гипосемы с определённой областью человеческого опыта (заметьте, не с вещью!) можно представить себе лишь в комбинации со всеми теми действиями и типами поведения, которые характерны для этой области в рамках данного человеческого коллектива... Язык порождает организацию опыта. Мы склонны смотреть на язык как на простую технику выражения, не трудясь объяснить себе, что язык - это прежде всего классификация и упорядочивание потока чувственного опыта, которое ведёт к упорядочиванию данного мира» (Мауро 2000: 162-164). 
Трактовка значения как идеального действия вполне согласуется с традицией, идущей от Л. С. Выготского, рассматривать значение как результат взаимодействия процессов, позволяющих субъекту коммуникации привести в соответствие конвенциальное экстериоризированное значение с тем, что актуализируется в индивидуальной картине мира на разных уровнях осознаваемости в виде различных ментальных репрезентаций как продуктов переработки перцептивного, когнитивного и аффективного опыта, в той или иной степени связанного с определённым языковым выражением и с конкретной ситуацией общения. Надо отметить, что и в фундаменте новейших исследований когнитивной модели обработки информации лежат знания в их единстве с эмоциями, чувствами и мотивацией, неаналитические методы обработки информации, человеческие навыки, хотя до недавнего времени, включая и когнитивный этап в развитии искусственного интеллекта, обработка информации жёстко ассоциировалась только со структурами знаний, игнорируя тем самым «образную» компоненту человеческого мышления.

На современном этапе развития когнитивной науки языковое знание определяется, как правило, в качестве отдельного модуля ментального пространства человека. При этом устанавливается, что семантический уровень конкретного языка не является универсальным, ибо в значительной степени зависит от устройства данного языка, семантический уровень как область конвенциональной образности соотносителен со структурами знаний, объективированными в языке, синтаксис же представляет конвенциальное отражение семантических структур (Кубрякова и др. 1996: 49-50). Таким образом «семантическая» память не отграничивается полностью от других структур знаний, т.е. семантический уровень понимается, скорее, как своеобразный доступ, направление для конструирования концептуальной структуры. Именно поэтому включённость значения как семантической сущности в ментальные структуры более высокого порядка позволяет переходить от языковых знаний к энциклопедическим, что в свою очередь даёт выход на индивидуальную картину мира как обязательное условие успешности взаимопонимания при общении. Соответственно, только концепты, по мнению многих исследователей, как базовая когнитивная сущность позволяют связывать смысл (не значение!) с употребляемым словом (Павилёнис 1983: 15), при этом «когнитивные сущности», что отмечалось, имеют перцептивные корни и эмоционально-оценочно переживаются субъектом коммуникации. Концепты существуют в ментальном пространстве индивида не в виде чётких понятий, а как «пучки» представлений, понятий, знаний, ассоциаций, переживаний, которые сопровождают каждое слово как языковое выражение: «... концепты не только мыслятся, они переживаются. Они - предмет эмоций, симпатий и антипатий, а иногда и столкновений» (Степанов 1998: 41).

С позиций современной психолингвистики каждый индивид формирует свою специфическую систему связей и ориентиров, организующих 
когнитивное пространство. Выведение так называемых функциональных ориентиров «вовне» требует перехода от интрапсихического к интерпсихическому, что возможно, как уже отмечалось, с помощью логической обработки информации и её вербализации, т.е. с привлечением конвенциальных значений семантического уровня, придающих этому процессу характер экстериоризации и позволяющих его продуктам соотносится с правилами описательной грамматики. В то же время функциональные ориентиры, или индивидуальные оперативные единицы мышления (личностные смыслы), могут не иметь знакового, т.е. конвенционального характера: «Личностные смыслы, из которых кристаллизуется мысль, могут иметь разный субстрат» (Человеческий фактор 1991: 29). Так, актуализация того или иного целостного фрагмента картины мира субъекта коммуникации как кванта его предшествующего опыта может определяться воспоминанием, или, как иногда образно говорят, «всплытием», какого-либо образа, представления, картины невербального характера. Например, сценарий «Моя первая любовь» и его события, равно как и чувства, отношения и переживания субъекта коммуникации, вплоть до его мировоззренческих установок, могут ассоциироваться с каким-нибудь мотивом, запахом духов и т.д. и т.п., или, наоборот, вполне возможно возникновение нетипичных (неожидаемых) ассоциаций при конвенциальном словесном знаке - вспомним хотя бы печально известное изречение: «При слове культура я сразу хватаюсь за пистолет».

По современным научным представлениям мысль изначально существует (зарождается) в виде целостного гештальта как своеобразного сгустка личностных смыслов (индивидуальных функциональных опор и ориентиров): «... исходным материалом для любой мысли является фонд энграмм; мысль рождается при их активной перегруппировке, новых объединениях; образные и «картинные» энграммы в правом полушарии связываются с их коррелятами в левом... связь полушарий означает фактически переход от целостного видения ситуации (лучше, фрагмента мира - Г. М.) к её расчленённому представлению, переход от гештальта - к его отдельным частям, от холистического образования - к составляющим его отдельным структурам, что лингвистически соответствует трансформации многомерных структур в линейно организованные, выбору из гештальта темы и ремы, топиков и комментов, противопоставлению данного и нового и т.п.» (Человеческий фактор 1991: 52). В модульных теориях организации когнитивного пространства человека, основанных на компьютерной метафоре, выделяют «лексикон», «оператор», «буфер» и собственно память, причём трактуются данные модули как разные виды памяти, которая в целом характеризуется динамичностью, и если собственно память - долговременна, то «лексикон», «оператор» и «буфер» работают в режиме кратковременной памяти, определяясь процессуальностью, возникающей при необходимости продуцирования или восприятия речи. Заметим, что при такой интерпретации «лекси- 
кон» соответствует семантическому уровню (СУ), а «оператор» и «буфер» коррелируют с разработанным в отечественной психолингвистике понятием внутренней речи (ВР) как таким психическим (ментальным) образованием, которое оказывается промежуточным звеном между замыслом речи и его языковым выражением.

В монографии «Речь как проводник информации» выдающийся российский психолингвист Н. И. Жинкин писал: «Речь - это действие, которое совершает один партнёр по отношению к другому для передачи мысли и смыслового воздействия... Человек слышит слова, состоящие из звуков: «Вон бежит собака», а думает при этом не о звуках и словах, а о собаке, и смотрит - где она бежит. Преобразование и интеграция (при семиотическом преобразовании - Г. М.) необходимы, потому что интеллект, для которого предназначается сообщение, не понимает естественного языка. У него есть собственный, специальный информационный язык (индивидуальные функциональные опоры и ориентиры - Г. М.). На этом языке он строит гипотезы, доказательства, делает выводы. Вот почему потребности коммуникации вызвали образование взаимодействующих кодов, которые сложились в единую систему: язык - звуковая речь - внутренняя речь - интеллект. Эта система является саморегулирующейся и способной к самоусовершенствованию. Противопоставленность двух дискретных кодов языкам интеллекта породила смешанный код - внутреннюю речь, которую нужно рассматривать как универсальный предметный код, ставший посредником не только между языком и интеллектом и между письменной и устной речью, но и между национальными языками» (Жинкин 1982: 48-49).

Столь пространная цитата из работы Н.И. Жинкина необходима, т.к. в ней в ней содержатся или даются основания ряду существеннейших для современных когнитивных исследований положений:

- обращение к языку как конвенциальной системе кодирования информации возникает при необходимости коммуникации;

- языковые выражения как в устной, так и в письменной формах представляют фрагмент картины мира субъекта коммуникации дискретно;

- языковые выражения не актуализируют у слушающего как партнёра по коммуникации языковые знания, а помогают ему ориентироваться в собственном когнитивном пространстве;

- у каждого субъекта коммуникации существует индивидуальная система функциональных опор и ориентиров в когнитивном пространстве;

- эта система (в иной терминологии - система личностных смыслов как квантов индивидуального опыта) обладает разнообразной субстанциональной природой, т.е. ментальные репрезентации могут быть как вербальные, так и образные, аналоговые;

- форма репрезентации знаний, в том числе и ассоциированных с языковыми выражениями, у индивида не является строго фиксированной 
и заданной заранее, а в значительной степени зависит от ситуации, в которой осуществлялся акт познания, и от когнитивной активности субъекта познания и коммуникации (от того, как он конструирует эту ситуацию и как представляет свои возможности в ней: ср.: Не повезло; Мне не везёт; Я невезучии; Везение обходит меня стороной и m.n.);

- $\quad$ ментальным пространством, где осуществляется «перевод мысли на конкретный язык», выступает внутренняя речь (в то же время это и процесс такого перевода), единицы которой обладают не только индивидуальным содержанием, но и пересекаются с конвенциальными, экстериоризированными единицами семантики - значениями, выступая первым звеном в дискретизации целостного гештальта (замысла речи), внутренняя речь не обладает стандартным набором грамматических правил и алфавитом своих единиц, поскольку не является ни строго дискретной, ни целиком аналоговой, это субъективный язык, который не осознаётся говорящим;

- у универсальный предметный код (УПК), или внутренняя речь как когнитивное пространство, это «стык речи и интеллекта», где и происходит переплетение и взаимное преобразование индивидуального знания и общего как достояния социума, это своеобразный язык-посредник, при участии которого замысел переводится на доступный для каждого партнёра в коммуникации язык;

- универсальный предметный код (внутренняя речь) является таковым, поскольку свойствен человеческому мозгу и обладает общностью для разных человеческих языков; внутренняя речь может применять любые сенсорные знаки, «подаваемые» памятью в зависимости от условий запечатления предметов и их связей отдельным субъектом, и в то же время, в соответствии со взглядами современных когнитивистов, неязыковая информация, как и языковая, репрезентируется в пропозициональной форме или может интерпретироваться в пропозициональных терминах;

- внутренняя речь не является высказыванием, а только его регулятором, поскольку здесь происходит не только расщепление целостного гештальта, но и структурирование и перераспределение информации при его линеаризации в ряд языковых выражений и, соответственно, речевых высказываний (ср.: «буфер» и «оператор» Ч. Осгуда), причём один и тот же объём информации может подаваться по-разному в разных условиях коммуникации и в зависимости от культурной традиции и выбранной говорящим коммуникативной стратегии, потому что даже замысел речи может корректироваться по мере осуществления акта коммуникации, что ещё раз подтверждает динамический и оперативный характер внутренней речи как типа памяти.

Существенным в эвристическом плане представляется и выделение в качестве единицы универсального предметного кода внутреннего слова, которое изначально в концепции Л. С. Выготского («Внутренняя речь есть речь для себя») понималось прежде всего как вербальная конвенциональная 
единица, выступающая знаком отдельной ситуации, и соответствовало идее «внутреннего (глубинного) предиката» (Выготский 1996: 317, 352-354). Подчеркнём, что акт глубинной предикации не равен суждению в логике и предложению в языке. На наш взгляд, в качестве внутреннего слова может выступать любая по своей природе ментальная репрезентация как единица универсального предметного кода, вне всяких сомнений, являющаяся квазизнаком - условной номинацией ситуации «для себя»: «Внутреннее слово - это условный знак ситуации «для себя», сгусток личностных смыслов, целый семантический комплекс, который на стадии его озвучивания, перевода во внешнюю речь и выведения во внешнее высказывание должен быть расчленён на части, соответствующие (в целях нормального общения) конвенциальным языковым значениям, обнаруживаемым в телах определённых языковых знаков. Внутреннее слово, этот зародыш будущего высказывания, ещё лишён грамматических признаков, это может быть и не слово естественного языка, а лишь его кусочек, намёк на него» (Человеческий фактор 1991: 64).

Таким образом, внутреннее слово является пропозициональным по своей сути, и здесь уместно отметить его важнейшую регулятивную функцию при порождении и / или восприятии речи - способность выступать актуализатором узлов ассоциативно-вербальных сетей пропозициональных структур (моделей) как форм хранения знаний и трансформатором других, образных и гештальтных форм в памяти человека: «В порождении и восприятии речи П. М. (пропозициональные модели - Г. М.) используются для репрезентации концептов глаголов и имён... При исследовании организации памяти П. М. являются важнейшим средством репрезентации семантической памяти, схем, скриптов и других структур знаний» (Кубрякова и др. 1996: 136). Следовательно, внутренняя речь выступает как оперативный тип памяти, с помощью внутренних слов актуализируются и структурируются знания, происходит пропозиционализация гештальтов и других ментальных структур хранения знаний, которые при выведении «вовне» претерпевают дискретизацию, когда происходит называние «для себя» посредством внутреннего слова, и конвенциализацию, когда внутреннее слово коррелирует со значениями семантического уровня при нахождении соответствующих лемм (ментальных репрезентаций лексикона естественного языка).

Если понимать знания в качестве структурированной и организованной информации, представляющей человеческий опыт как результат познания мира, то слова естественного языка выступают важнейшим средством организации этого опыта, хотя, по мнению многих исследователей, слова, подобно другим языковым выражениям, дают только намёки для конструирования концептуальной структуры, поскольку не существует прямого кодирования понятий словами или раскодирования слов в понятия: «...естественный язык сам по себе вообще ничего не выражает, если не предполагается определенная его интерпретация. <..> . . о выражении с помощью языка некоторого 
концепта можно говорить, понимая под этим фиксацию (благодаря кодирующей функции языка) или построение (благодаря манипулятивной его функции) определенного концепта в другой (принимающей данное выражение) концептуальной системе, в тривиальном случае - в той же. Сами вербальные выражения скорее следует рассматривать - не игнорируя при этом их принципиально важной функции: символической фиксации, концептуальных структур, манипуляции ими и усвоения новых концептуальных структур - в качестве меток на непрерывном пространстве смысла, имеющих кроме своей социальной природы и социальную функцию: служить средством коммуникации. Выделенные нами функции кодирования и манипулирования концептами объясняют возможность «передачи» информации посредством текста, когда в одном конце линии «передачи» концепты, принадлежащие определенным концептуальным системам, кодируются текстом (в исторической перспективе - «консервируются» текстом), а в другом - этот текст декодируется в определенных концептуальных системах » (Павилёнис 1983: 115). Тем не менее, лексикон рассматривается, в частности, в концепции того же Ч. Осгуда (см.: Osgood 1984), как один из важнейших механизмов когнитивной переработки информации, связанный с уровнем репрезентации и осуществляющий переработку по двум линиям: от воспринимаемых знаков-перцептов (перцептивных и языковых знаков) к значениям и от интенций субъекта к программе деятельности, языковой либо иной. Как отмечает А. А. Залевская, в концепции Ч. Осгуда то, что хранится в ментальном лексиконе, «это очень большой набор связей между знаками (перцептами) и кодами семантических признаков... При этом подчёркивается происхождение семантических признаков из опыта, их формирование в качестве наиболее обобщённого вида знания о мире и обязательность эмоционально-оценочного отношения к носителям признаков (последнее выражается через биполярность признаков)» (Залевская 2000: 138-139).

Идеи, высказанные Ч. Осгудом, как и сам термин ментальный лексикон, очень активно используются в современных работах когнитивного направления, развиваются в исследованиях лингвистов и психологов, философов языка и психолингвистов, однако, к сожалению, крайне слабо связываются с интеллектуальными наработками в области семантики традиционного языкознания и предвосхитившими время достижениями отечественной теории речевой деятельности. Наиболее очевидно это прослеживается при разработке содержания понятия ментальный лексикон и использовании в экспланаторных целях, т.к. несмотря на «модность» и повсеместность применения, единое определение и толкование его фактически отсутствуют: либо это индивидуальный запас слов, либо репрезентации слов в долговременной памяти человека, либо «хранилище» слов в памяти, либо «память слов», либо индивидуальная часть общенационального словарного запаса, хранимая в памяти, подобно лексемам в словарях, и т.д. Данная в «Кратком 
словаре когнитивных терминов» дефиниция, согласно которой ментальный лексикон - это «система, отражающая в языковой способности знания о словах и эквивалентных им единицах, а также выполняющая сложные функции, связанные не только с указанными языковыми единицами, но и стоящими за ними структурами представления экстралингвистического (энциклопедического) знания» (Кубрякова и др. 1996: 97), по справедливому наблюдению А. А. Залевской, вызывает следующие вопросы: а) Что понимается под «знанием о словах»? б) Какие функции выполняет слово как единица ментального лексикона? в) Как соотносятся знание о словах и энциклопедическое знание? г) Как осуществляется доступ к единицам ментального лексикона? д) Как организован ментальный лексикон? (Залевская 2000: 141).

Частично ответы на эти вопросы, порою взаимно противоречащие, можно найти в других статьях данного словаря, в которых утверждается, что единицы ментального лексикона как части концептуального уровня напрямую связаны с языковыми формами как носителями определённых значений (Кубрякова и др. 1996: 95); что ментальным лексиконом называют совокупность вербальных репрезентаций (Кубрякова и др. 1996: 158); что слова и прочие языковые единицы как «языковые» репрезентации активизируют те сущности, знаковыми заместителями которых они являются - они возбуждают в памяти человека связанные с ними концепты (Кубрякова и др. 1996: 159); что ментальный лексикон - это метафора, обозначающая обширную часть языкового знания, включая элементарных носителей языкового значения и их формы, а также ментальной организации, и наконец, что, по-видимому, следует отказаться от метафоры ментального лексикона как хранилища информации, к которому человек обращается по методу использования обычного словаря (Кубрякова и др. 1996: 152-153). Последние два утверждения делают обоснованным замечание А. А. Залевской об имеющейся в работах по искусственному интеллекту тенденции приравнивания ментального лексикона к семантической памяти, т.е. области семантических конвенциальных значений, или семантическому уровню. Надо сказать, что довольно часто и сами приверженцы понятия ментального лексикона как особого, отдельного ментального пространства предоставляют повод для утверждений о его избыточности, поскольку, будучи преимущественно представителями когнитивной психологии, они абсолютно не учитывают научные знания, разработанные в области семантики языковедами и в теории речевой деятельности психолингвистами.

Так, М. Гарман, определяя в качестве единиц ментального лексикона а) репрезентации слов (по сути, лексические значения), б) репрезентации словоформ (соответственно, грамматические значения) и в) связи между значениями слов и общим знанием (опосредование семантическим значением части концептуальной информации как достояния индивида, но не общего знания как достояния социума), при разработке вопросов понимания 
речи тем самым, действительно, «помещает» ментальный лексикон в область семантического уровня. И напротив, В. Левелт интерпретирует ментальный лексикон в виде хранилища информации (знаний) декларативного типа о словах как лексических единицах, требующихся для выражения конвенциального значения, выделяя при этом в качестве основных единиц ментального лексикона леммы, которые обладают не только лексическим и грамматическим значениями, но и прагматическим, несущим скорее личностные смыслы, т.е. приближающим лемму к внутреннему слову. В данном случае, рассматривая проблемы продуцирования речи, исследователь обращает внимание на процесс экстериоризации знаний индивида, их перевод из интрапсихической репрезентации в интерпсихическую, основанную на конвенциональной образности, и тем самым фактически вторгается в пространство внутренней речи, приписывая функции её единиц составляющим ментального лексикона (см. подробнее: Залевская 2000: 143-149).

Не представляется состоятельным в свете анализируемого материала и положение, поддерживаемое некоторыми когнитивистами, о включённости энциклопедических знаний в содержание ментального лексикона, в то время как разведение языкового уровня значений и уровня концептуальной репрезентации подкрепляется достаточно обоснованными аргументами, согласно которым смешение семантического знания с концептуальным знанием приводит к неразличению семантических структур и концептуализаций, индивид может иметь различные виды знания, никак не связанные с семантической структурой языка, а отдельные типы высказываний допускают интерпретации, которые не являются частью чисто языкового значения. В этой связи уместным становится замечание Ч. Филлмора о том, что значение слова может быть понято только через обращение к структурированному фоновому знанию, основывающемуся на опыте и убеждениях субъекта коммуникации. Таким образом, понятие ментальный лексикон, на наш взгляд, можно использовать лишь в качестве обобщающего и недифференцированного при определении типа оперативной памяти субъекта как ментального пространства, объединяющего области конвенциальных значений (семантический уровень) и функциональных индивидуальных опор и ориентиров, или личностных смыслов (внутренняя речь), актуализированного в процессе коммуникации - при производстве и / или восприятии речи.

Итак, семантический уровень включает в себя область кодифицированных и социально закрепленных значений языковых выражений, соотносительных со смыслами индивидуальных концептуальных схем, которые также суть формы общественного опыта, усваиваемые субъектом в процессах социального взаимодействия, но формы некодифицированные. Наряду с индивидуально-личностными смыслами, эти смыслы в тех или иных конфигурациях формируют определенный концепт в индивидуальном образе мира. Значения суть результаты идеальных действий по организации доступа к кон- 
цептуальной схеме индивида и упорядочивания опыта как различных структур знаний и представлений о мире, поскольку они могут соотносить между собой не только различные репрезентации, но и разные концепты в когнитивных пространствах как отдельного субъекта, так и общающихся людей, обеспечивая при коммуникации координацию их концептуальных схем.

Внутренняя речь предстает как когнитивное пространство, в котором осуществляется процесс перевода «языка мысли» на естественный язык и происходит дискретизация целостных гештальтов с помощью любых ментальных репрезентаций. При этом «внутреннее слово» как единица внутренней речи предстает как квазизнак (знак для себя), поскольку актуализирует индивидуальные ассоциативно-вербальные сети пропозициональных структур и трансформирует образные и гештальтные структуры знаний и представлений о мире.

Ментальный лексикон понимается как набор связей (ассоциаций) между «внутренними словами» (перцептами) и кодами семантических признаков (значениями), а также как когнитивная структура языковых знаний, выполняющая сложные функции по обеспечению этих связей. Таким образом, ментальный лексикон может заключать в себе когнитивные области конвенциальных значений (семантики) и внутренней речи (стыка интеллекта и языка) как соотносительные между собою, но разные по природе гносеологических образов системы представлений, входящие в концептуальные структуры и способные актуализировать их в процессах порождения и понимания речи. Координация понятий семантического уровня, внутренней речи и ментального лексикона позволяет интегрировать достижения разных наук и придает им значительно большую объяснительную силу, чем автономное применение.

\section{Библиография}

Выготский Л. С. (1996), Мьиление и речь. Психологические исследования, Москва: Лабиринт. Жинкин Н. И. (1982), Речь как проводник информации, Москва: Наука.

Залевская А. А. (2000), Введение в психолингвистику, Москва: Рос. гос. гуманит. ун-т.

Кибрик А. Е. (2001), Очерки по общим и прикладным вопросам языкознания (универсальное, типовое и специффичное в языке), 2-е изд., Москва: Эдиториал УРСС.

Кобозева И. М. (2000), Лингвистическая семантика, Москва: Эдиториал УРСС.

Кубрякова Е. С., Демьянков В. З., Панкрац Ю. Г., Лузина Л. Г. (1996), Краткий словарь когниmивных терминов, Москва: МГУ.

Леонтьев А. А. (2001), Язык и речевая деятельность в общей и педагогической психологии: Избранные психологические труды, Москва: Московский психолого-социальный институт, Воронеж: НПО «МОДЭК».

Мауро Т. Де. (2000), Введение в семантику, Москва: Дом интеллектуальной книги.

Павилёнис Р. И. (1983), Проблема смысла: современный логико-философский анализ языка, Москва: Мысль. 
Степанов Ю. С. (1998), Константы. Словарь русской культуры. Опыт исследования, Москва: Школа «Языки русской культуры».

Кубрякова Е. С., Шахнарович А. М., Сахарный Л. В. (1991), Человеческий фактор в языке: Язык и порождение речи, Москва: Наука.

Osgood Ch. E. (1984), Toward an abstract performance grammar, [In:] Talking minds: The study of language in cognitive science, Cambridge, p. 147-179.

\title{
Gennadij Manajenko
}

\section{Three Scientific Images of Abstract Object}

\begin{abstract}
Summary
The article presents a critical analysis of three theoretical concepts correlation - semantic level, inner speech, mental vocabulary, represented, respectively, in the traditional linguistics, psycholinguistics and cognitive linguistics. These concepts are related to one abstract object - a mental space which surfaces in the communication process - the production and / or perception of language which combines the area of conventional values (semantic level) with functional individual support and guidance, or personal meanings (inner language).
\end{abstract}

